\title{
Unusual cause of abdominal distension: Infected abdominal cerebrospinal fluid pseudocyst
}

\author{
*Vindika Prasad Sinhabahu ${ }^{1}$, Sarah Jamison ${ }^{2}$, Damaya Rasanathan ${ }^{2}$, Heidi Baker ${ }^{2}$
}

Sri Lanka Journal of Child Health, 2019; 48(3): 273-274

DOI: http://dx.doi.org/10.4038/sljch.v48i3.8769

(Key words: Abdominal distension, abdominal cerebrospinal fluid pseudocyst)

\section{Case report}

A twenty two month old boy presented to the Emergency Department with abdominal distension. $\mathrm{He}$ has a background of global developmental delay and achondroplasia. He had foramen magnum stenosis with upper cervical myelopathy which required surgical decompression at 4 months of age. A ventriculo-peritoneal (VP) shunt was inserted for obstructive hydrocephalus at 9 months of age. It was revised 8 months later. Bilateral inguinal hernia repair was done when he was 11 months. He has obstructive sleep apnoea and requires overnight continuous positive air pressure.

He presented with a one week history of progressive abdominal distension and irritability. Oral intake and urine output were satisfactory. There was no history of vomiting or fever. He had an enema four days prior to this presentation for possible constipation as the cause of his abdominal distension. Since the enema, he had regular bowel motions daily. On examination, he was irritable with a pulse rate of $156 / \mathrm{min}$ and a respiratory rate of $36 / \mathrm{min}$. Oxygen saturation in air was $95 \%$. Anterior fontanelle was open and not bulging. Abdomen was markedly distended without tenderness. It was resonant to percussion with normal bowel sounds. Features of raised intracranial pressure and focal neurological signs were absent.

A full blood count showed a neutrophil leucocytosis, thrombocytosis and anaemia (white blood cells - 18,320/ cu mm, neutrophils $67.4 \%$, platelet count $-747,000 / \mathrm{cu} \mathrm{mm}, \mathrm{Hb}-9.1 \mathrm{~g} / \mathrm{dl}$.). C-

${ }^{1}$ Fellow, ${ }^{2}$ Consultant, Children's Emergency
Department, Starship Children's Health, Auckland,
New Zealand
${ }^{* C o r r e s p o n d e n c e: ~ s i n b a d . l k @ g m a i l . c o m ~}$
iD orcid.org/0000-0003-0065-2845 (Received on 14 November 2017: Accepted after revision on 22 December 2017)

The authors declare that there are no conflicts of interest

Personal funding was used for the project.

Open Access Article published under the Creative

Commons Attribution CC-BY (C) (†) License reactive protein was $114 \mathrm{mg} / \mathrm{l}$. An abdominal X-ray showed distended bowel loops without any evidence of obstruction or perforation (Figure 1).

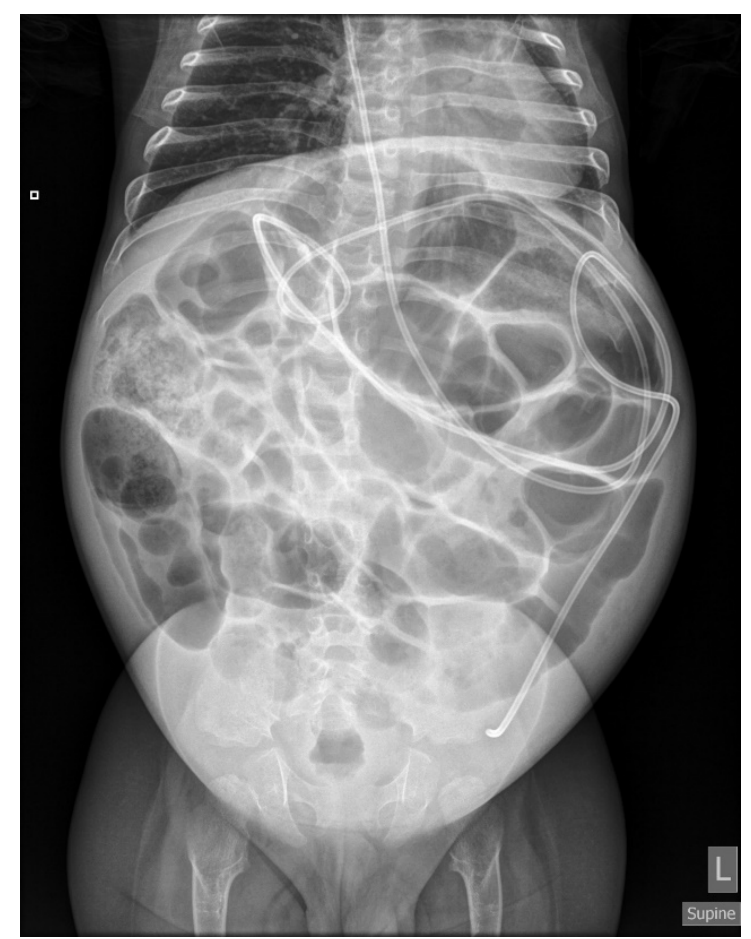

Figure 1: Abdominal radiograph showing gaseous distension and paucity of gas in lower abdomen

An ultrasound scan (USS) of the abdomen showed multiple large loculated fluid collections within the lower abdomen. The tip of the VP shunt was not visualised (Figure 2).

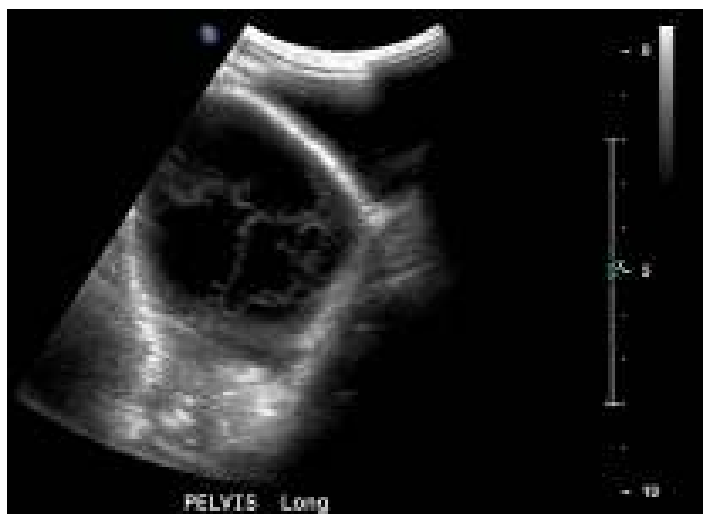

Figure 2: Ultrasound scan of abdomen showing septated cyst in peritoneal cavity 
On the basis of the USS, he was diagnosed as having an abdominal CSF pseudocyst (ACP). The VP shunt was externalized and connected to an external drain. A CSF culture revealed Staphylococcus epidermidis which was resistant to penicillin and flucloxacillin and sensitive to vancomycin. He was treated with intravenous vancomycin for 21 days.

Subsequent USSs of the abdomen showed resolution of the abdominal cysts. A ventriculoatrial shunt was inserted after clearing the CSF infection. Four months after initial presentation, he was well without further complications.

\section{Discussion}

Abdominal complications of VP shunts include peritonitis, ascites, bowel and abdominal wall perforation and inguinal hernias ${ }^{1,2}$. ACP is a rare complication of VP shunts and the incidence is less than $1 \%{ }^{3,4}$. Abdominal pain, abdominal mass, distension, intestinal obstruction, and shunt dysfunction are common presentations of $\mathrm{ACP}^{2}$. ACP can occur from 3 weeks to 5 years since the last shunting procedure ${ }^{4}$.

Computed tomography (CT) scan of abdomen and USS of abdomen are used to diagnose APC in children. An abdominal USS is the preferred method of diagnosis in children due to the absence of radiation risk, and can be repeated to assess the clinical course of ACP. Main criteria for the diagnosis are presence of an intraperitoneal fluid collection with well-defined margins and the identification of the distal tip of VP shunt near or within the $\mathrm{APC}^{5-8}$. Pathophysiology is not clear though infections, allergic reactions to silicone or ethylene oxide and previous abdominal surgeries are known predisposing factors ${ }^{2}$. Staphylococcus aureus, Staphylococcus epidermidis and Propionibacterium acnes are the common bacterial isolates from $\mathrm{ACP}^{1}$. The preferred treatment include CSF diversion and treatment of the infection followed by the placement of an alternative shunt such as ventriculo atrial or ventriculo pleural shunt ${ }^{6}$. The peritoneum can be utilized for shunting subsequently.

CSF infection and a history of minor abdominal surgery (bilateral inguinal hernia repair) were the predisposing factors present in our patient. Our patient responded well to antibiotics and CSF diversion resulting in a resolution of the ACP. ACP should be considered in a child with a VP shunt who presents with abdominal distension. An abdominal USS is the investigation of choice in children for prompt diagnosis and follow up of ACP.

\section{References}

1. Yuh S-J, Vassilyadi M. Management of abdominal pseudocyst in shunt-dependent hydrocephalus. Surgical Neurology International 2012; 3:146.

https://doi.org/10.4103/2152-7806.103890

PMid: 23230527 PMCid: PMC3515935

2. Buyukyavuz BI, Duman L, Karaaslan T, Turedi A. Hyponatraemic seizure due to huge abdominal cerebrospinal fluid pseudocyst in a child with ventriculoperitoneal shunt: a case report. Turkish Neurosurgery 2012; 22(5): 656-8.

PMid: 23015347

3. Badiane SB, Sakho Y, Kabre A, Ba MC, Fall B, Ndoye N, et al. Peritoneal pseudocysts: complications of ventriculoperitoneal shunts. Apropos of 3 cases. Dakar Medical 1997; 42(2):149-51.

PMid: 9827140

4. Ghritlaharey RK, Budhwani KS, Shrivastava DK, Srivastava J. Ventriculo-peritoneal shunt complications needing shunt revision in children: a review of 5 years of experience with 48 revisions. African Journal of Paediatric Surgery 2012; 9(1):32-9.

PMid: 22382102

5. Erşahin Y, Mutluer S, Tekeli G. Abdominal cerebrospinal fluid pseudocysts. Child's Nervous System 1996; 12(12):755-8. https://doi.org/10.1007/BF00261593

6. Salomão JF, Leibinger RD. Abdominal pseudocysts complicating CSF shunting in infants and children. Report of 18 cases. Pediatric Neurosurgery 1999; 31(5):2748.

PMid: 10681683

7. Gaskill SJ, Marlin AE. Pseudocysts of the abdomen associated with ventriculoperitoneal shunts: a report of twelve cases and a review of the literature. Pediatric Neuroscience 1989; 15(1):23-7. https://doi.org/10.1159/000120436

8. Wang B, Hasadsri L, Wang H. Abdominal cerebrospinal fluid pseudocyst mimicking full-term pregnancy. Journal of Surgical Case Reports. 2012; 2012(7):6. https://doi.org/10.1093/jscr/2012.7.6 PMid: 24960731 PMCid: PMC3649563 